To keep abreast of advancing knowledge of drugs and their actions is no mean task. The author has succeeded in presenting a balanced picture of modern drug therapy without a burden of detail.

Older drugs, for example Mist Ferri et Ammon. Cit. and Crystal Violet, as an anthelmintic, are deleted. Newer ones, such as tranquillizing drugs and cortisone preparations, are added.

The re-written chapter on fluid balance gives a simple theoretical explanation of clinical infusions. It is regrettable that notes on the term milligramequivalent are omitted, but the author, no doubt, has good reason for this.

It remains the best book of its kind for nurses. M.A.L.

\section{THE CLINICAL MANAGEMENT OF VARICOSE VEINS}

By D. W. Barrow, M.D. Second edition. Pp. xiii + r69, with 70 illustrations. London: Cassell \& Co. Ltd. 1957. 45s.

It has been a pleasure to read this short monograph on the clinical management of patients with varicose veins. Short chapters on anatomy, physiology and pathology are followed by a concise, practical account of the methods the author recommends for the investigation and treatment of these patients. The emphasis has been upon the practical side of the problem. This is not a complete monograph and does not pretend to be one, but it presents in a readable form the author's views upon how to treat patients with varicose veins and their commoner complications.

It is of interest that the approach to these patients appears to be nearly the same in Milwaukee, Wisconsin, as in Paddington, London.

\section{C.G.R.}

\section{PROGRESS IN HEMATOLOGY}

\section{Volume I}

Edited by L. M. Tocantins, M.D. Pp. ix + 336, illustrated. New York and London: Grune and Stratton Inc. 1956 . $\$ 9.75$.

A periodic survey of the progress of haematology is the chief intention of this publication, and the frequency of future volumes will depend on the advances in haematology, so it is stated in the introduction.

The 16 papers gathered here are almost without exception masterpieces of reviews of their subjects written by the masters themselves. Though advances have been made since their writing making the papers themselves partly out of date at the time of publication, the overall picture is well presented. Perhaps, unfortunately, few of the papers have summaries and the references are mostly very awkwardly arranged.

The only non-American team amongst the contributors are Drs. Ungley and Thompson of New- castle, who discuss very reasonably gastric intrinsic factor and Vitamin $B_{12}$ inter-relationships. Various aspects of iron deficiency anaemia, of haemolytic $\stackrel{\varnothing}{\Omega}$ disease, abnormal haemoglobins, systemic lupus $C$ erythematosus and polycythaemia are presented. $\overrightarrow{\vec{B}}$ The auto-immune thrombocytopenias, acute fibri- $\stackrel{5}{\rightarrow}$ nogen deficiencies and agammaglobulinaemia are $\bar{O}$ well covered. A surgeon (A. F. di Palma of Philadelphia) provides guiding principles in the surgery of haemophilic patients-a very useful outline.

Burchenal and Ellison's essay on the chemotherapy of leukaemia is perhaps the best written and best arranged in an already fine collection. Valentine's survey of the biochemistry and enzymatic activities of leucocytes in health and disease is a very balanced critical review.

Although this book fairly represents the growth and the growing importance of haematology during the last 20 or so years, and although the book will certainly be useful for every haematologist, this reviewer cannot help feeling that the place for such papers is in journals of haematology, which are themselves perhaps already too numerous. $\mathrm{He}$ is, however, very glad to see them collected in one volume.

E. $\mathbf{N}$.

\section{FUNDAMENTALS OF CLINICAL FLUOROSCOPY}

By Charles B. Storch, M.D. Second edition Pp. xiii +305 , with 318 illustrations. New Yor and London: Grune and Stratton Inc. 1 956. \$8.75.

Dr. Storch's book is the second edition of a work previously published in $195^{\circ}$. It covers in great detail the practical aspects of radiological $\frac{\otimes}{\circ}$ screening and as such is addressed primarily to $\varnothing$ students of radiology.

The mode of presentation is perhaps more $\frac{3}{3}$ adapted to American than to British students, many of whom will find the 'Question and Answer' type of legend beneath diagrams rather irritating. However, the views expressed are generally comprehensive and sound, and will prove'most helpful to the trainee radiologist.

D.S.

\section{CYTOLOGIC TECHNICS For Office and Clinic}

By H. E. Nieburgs, M.D. Pp. viii +232, with I71 N illustrations. New York and London: Grune and Stratton Inc. 1956. $\$ 7.75$.

Although some may disagree with the statement $\omega$ in the preface that 'cancer detection and diagnosis? has been greatly enhanced by the study of ex-co foliative cytology,' there is no doubt that this comparatively short book is a very useful one. It? avoids mostly purely cytological details and presents 0 the techniques used in the surgery or clinic or even 0 